\title{
Robotic ureteral reimplantation for the management of ureterovaginal fistula: four cases at a single center
}

\author{
Changwei Yuan", Jie Wang", Sida Cheng", Zhihua Li, Chunru Xu, Weijie Zhu, Shubo Fan, Kunlin Yang, \\ Xuesong Li, Liqun Zhou \\ Department of Urology, Peking University First Hospital, Institute of Urology, Peking University, National Urological Cancer Center, Beijing, \\ China \\ Contributions: (I) Conception and design: C Yuan, J Wang; (II) Administrative support: K Yang, X Li, L Zhou; (III) Provision of study materials or \\ patients: W Zhu, S Fan; (IV) Collection and assembly of data: Z Li, C Xu; (V) Data analysis and interpretation: S Cheng; (VI) Manuscript writing: \\ All authors; (VII) Final approval of manuscript: All authors. \\ \#These authors contributed equally to this work. \\ Correspondence to: Kunlin Yang; Xuesong Li. Department of Urology, Peking University First Hospital, Institute of Urology, Peking University, National \\ Urological Cancer Center, No. 8 Xishiku St, Xicheng District, Beijing 100034, China. Email: yangkunlin12345@163.com; pineneedle@sina.com.
}

\begin{abstract}
Background: To describe our initial experience with robotic ureteral reimplantation for the management of ureterovaginal fistulas.

Methods: Between January 2018 and January 2020, four patients received robotic ureteral reimplantation for ureterovaginal fistulas. All patients were diagnosed based on anterograde urography and computed tomography urography (CTU). Follow-up was performed with magnetic resonance urography and renal ultrasound as well as the clinical assessment of symptoms.

Results: The mean age of all patients was 50.3 (range, 37-65) years. The cause of the ureterovaginal fistula in four patients was due to a previous hysterectomy. The mean time from fistula diagnosis to robotic repair surgery was 14.5 (range, 3-36) months. All robotic procedures were successfully performed without intraoperative complications or open conversion. The mean operative time was 137 (range, 116-171) minutes, and the mean estimated blood loss was 25 (range, 10-50) mL. No postoperative complications that were high grade (grade III and IV) occurred within one month of surgery. Patients had the double-J (D-J) stents removed 2 months after surgery and the nephrostomy tubes removed 3 months after the operation. There was a $100 \%$ success rate without serious complications, such as the leakage of urine and side progressive hydronephrosis, during the 6 to 24 months of follow-up.
\end{abstract}

Conclusions: Our initial results and experience showed that robotic ureteral reimplantation for the management of ureterovaginal fistula is safe and feasible.

Keywords: Ureterovaginal fistula (UVF); robotic repair; ureteral reimplantation; ureteral reconstruction

Submitted May 21, 2021. Accepted for publication Aug 26, 2021.

doi: 10.21037/tau-21-454

View this article at: https://dx.doi.org/10.21037/tau-21-454

\section{Introduction}

Ureterovaginal fistula (UVF) is an abnormal opening between the ureter and vagina and causes a continuous outflow of urine from the vaginal fistula. Patients' wet feeling and foul smell associated with the outflow of urine cause social difficulties for the patients. UVF is a genitourinary fistula, and the incidence of UVF ranges from $0.5 \%$ to $2.2 \%$ for benign gynecologic cases without cystoscopy $(1,2)$. Recent reports show that there are urinary system injuries in approximately $1 \%$ of all obstetric and gynecologic surgeries, with $30 \%$ in the ureter and $70 \%$ in the bladder $(3,4)$. Risks for developing a UVF are as follows: obesity, endometriosis, pelvic inflammatory disease, 
Table 1 Summary of perioperative outcomes

\begin{tabular}{|c|c|c|c|c|c|c|c|c|c|c|c|}
\hline No. & Age & $\begin{array}{c}\text { BMI } \\
\left(\mathrm{kg} / \mathrm{m}^{2}\right)\end{array}$ & The etiology of UVF & $\begin{array}{c}\text { Symptom } \\
\text { onset after } \\
\text { hysterectomy } \\
\text { (days) }\end{array}$ & $\begin{array}{l}\text { From fistula } \\
\text { diagnosed to } \\
\text { robotic surgery } \\
\text { (months) }\end{array}$ & Sides & $\begin{array}{c}\mathrm{OT} \\
\text { (mins) }\end{array}$ & $\begin{array}{l}\mathrm{EBL} \\
(\mathrm{mL})\end{array}$ & $\begin{array}{l}\text { Post- } \\
\text { OPH } \\
\text { (days) }\end{array}$ & $\begin{array}{l}\text { Post-OPC } \\
\text { (C-D grade) }\end{array}$ & $\begin{array}{l}\text { Follow-up } \\
\text { (months) }\end{array}$ \\
\hline 1 & 65 & 23.4 & $\begin{array}{c}\text { Cervical cancer/open } \\
\text { hysterectomy }\end{array}$ & 1 & 12 & Right & 149 & 10 & 5 & II (fever) & 24 \\
\hline 4 & 48 & 30.0 & $\begin{array}{c}\text { Carcinoma of the endometrium/ } \\
\text { open hysterectomy }\end{array}$ & 3 & 36 & Left & 122 & 20 & 4 & No & 6 \\
\hline
\end{tabular}

UVF, ureterovaginal fistula; LS., laparoscopy; BMI, body mass index; OT, operative time; EBL, estimated blood loss; OPH, operative hospitalization; OPC, operative complications.

radiation, cancer, and history of vascular or colorectal surgery (5).

Regarding the techniques of UVF surgery, open surgery has gradually been replaced by minimally invasive surgery, such as laparoscopy or robotic-assisted surgery. Laparoscopic surgery for UVF is usually performed by highly skilled surgeons because it is technically demanding, but robotic-assisted surgery can reduce these difficulties. Robotic-assisted surgery provides three-dimensional and magnified vision, an improved ability to work in limited anatomic spaces and a technique to precisely suture the pelvis $(6,7)$, which has significant advantages over conventional laparotomy or laparoscopy. In this study, we reported our initial outcomes of the management of UVF. The present study should be assigned to stage I according to the IDEAL recommendation (8).

We present the following article in accordance with the STROBE reporting checklist (available at https://dx.doi. org/10.21037/tau-21-454).

\section{Methods}

\section{Clinical materials}

Between January 2010 and January 2021, 41 patients were admitted to the hospital with a diagnosis of UVF. Thirtyseven patients with UVFs who underwent open repair surgery or laparoscopic surgery were excluded, and four patients who underwent robotic ureteral reimplantation from January 2018 to January 2020, which was performed by one surgeon, were recruited. We retrospectively analyzed the four patients' demographics and perioperative variables, including operative time, estimated blood loss (by estimating the blood volume in the suction container), maintenance drain time, hospitalization stays and complications, and follow-up data, which are recorded in Table 1. This study was approved by the Ethics Committee of Peking University First Hospital, and informed consent was obtained from all patients.

\section{Presurgical evaluation}

Preoperative radiographic examinations, such as antegrade pyelography, computed tomography urography (CTU), and cystoscopy, were performed. These patients were diagnosed by preoperative antegrade pyelography (Figure 1). CTU demonstrated that contrast could be seen in the vagina, and the lesion was located distal to the ureter. Cystoscopy showed that the ipsilateral ureteral orifice had poor urinous outflow, and light-yellow fluid flowing out from a small hole of the top of the vagina could be seen (Figure 1). Preoperative three-dimensional image reconstruction was applied to evaluate the relationship between the ureter and adjacent organs to assist in planning the surgery (Figure 2). To dissect the ureter easily, a ureteral stent or nephrostomy tube was suggested. Nephrostomy was finished in three outpatients, and in case 3 , who did not have an obvious upper urinary tract obstruction, surgery was not performed. The indications for robotic procedures for patients with UVFs were as follows: (I) repeated vaginal leakage affected the patient's life and work and patients with recurrence of urine leakage after double-J stent removal; (II) there was a gradual increase in hydronephrosis, which affected renal function; (III) the patients could not tolerate palliative 

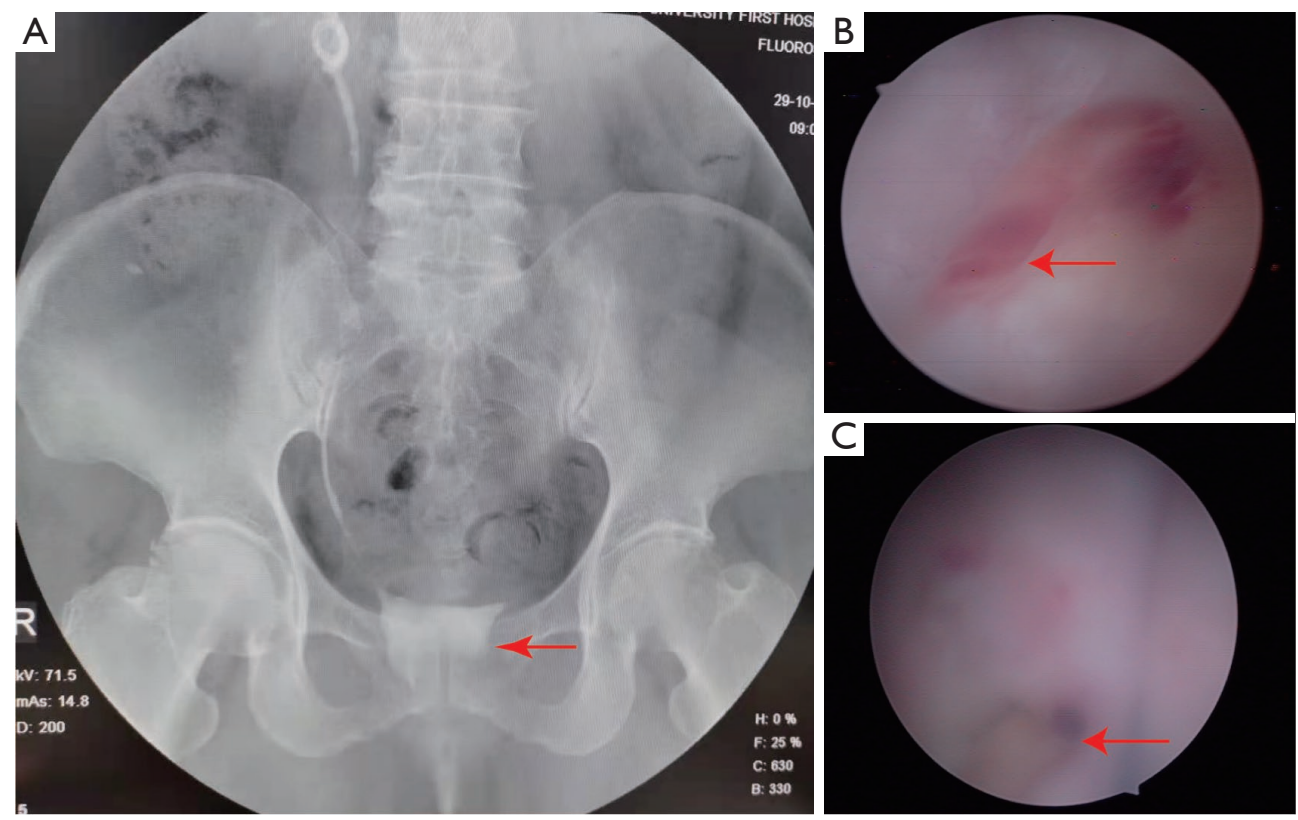

Figure 1 Preoperative urography and endoscopy showed a ureterovaginal fistula. (A) Antegrade pyelography through nephrotomy tube demonstrated that the contrast agent leaked into the uterus and vagina (red arrow). (B) Cystoscopy showed that there was edema of the ureteral orifice (red arrow). (C) Cystoscopy was used to examine the vagina and light-yellow fluid that flowed out from a small hole of the top of vagina can be seen (red arrow).

treatments such as double-J stents and nephrostomy and were expected to undergo robotic repair surgery. Patients were excluded if they had coagulation dysfunction, could not tolerate anesthesia and surgery, or had an uncontrolled acute urinary tract infection.

\section{Surgical techniques}

After general anesthesia, the patient was placed in a dorsal lithotomy position with the table in steep Trendelenburg. Access was achieved using a Veress needle, and five abdominal ports were placed (Figure $3 A$ ). Following port placement and separation of abdominal pelvic adhesions, the ureter was identified at the crossing of the iliac vessels and dissected carefully in an annular manner. The ureter was dissected free to the level of the UVF, which was recognizable because of obvious scar tissue located at the distal ureter (Figure 3B). Then, the fibrous fistula tract was excised, and the distal remaining tract was cauterized. The diseased tissue of the ureter was excised and sent for pathological analysis, and the ureter was trimmed to healthy edges using robotic shears. The bladder was separated from the lower uterine segment and vagina by blunt and sharp dissection. With the bladder expanded, a tension-free anastomosis could be created at the intended cystotomy site. A small incision was made in the lateral posterior wall of the bladder. The D-J stent was pulled back to the bladder through the hole to allow for the anastomosis. A mucosal to mucosal anastomosis was created between the spatulated ureter and the bladder with 4-0 Vicryl (Figure 3C) with 4 sutures to strengthen the anastomosis. The psoas hitch was required to ensure tension-free ureteral reimplantation (Figure 3D). Finally, an omental flap was wrapped around the ureter as a layer between the ureter and vagina to reduce the risk of leakage and effectively improve the vascular supply (Figure 3E). Finally, a Foley catheter was left in the bladder, and a pelvic drain was placed adjacent to the anastomosis.

\section{Postoperative care and follow-up}

After the operation, patients had an indwelling Foley catheter, a drain near the anastomosis, and a D-J stent placed. Catheters remained in the three patients who underwent ipsilateral nephrostomy preoperatively. The Foley catheters were removed within 1 to 2 weeks postoperatively. The drain was usually removed when the output was $<50 \mathrm{~mL}$ after the operation. Radiography was 

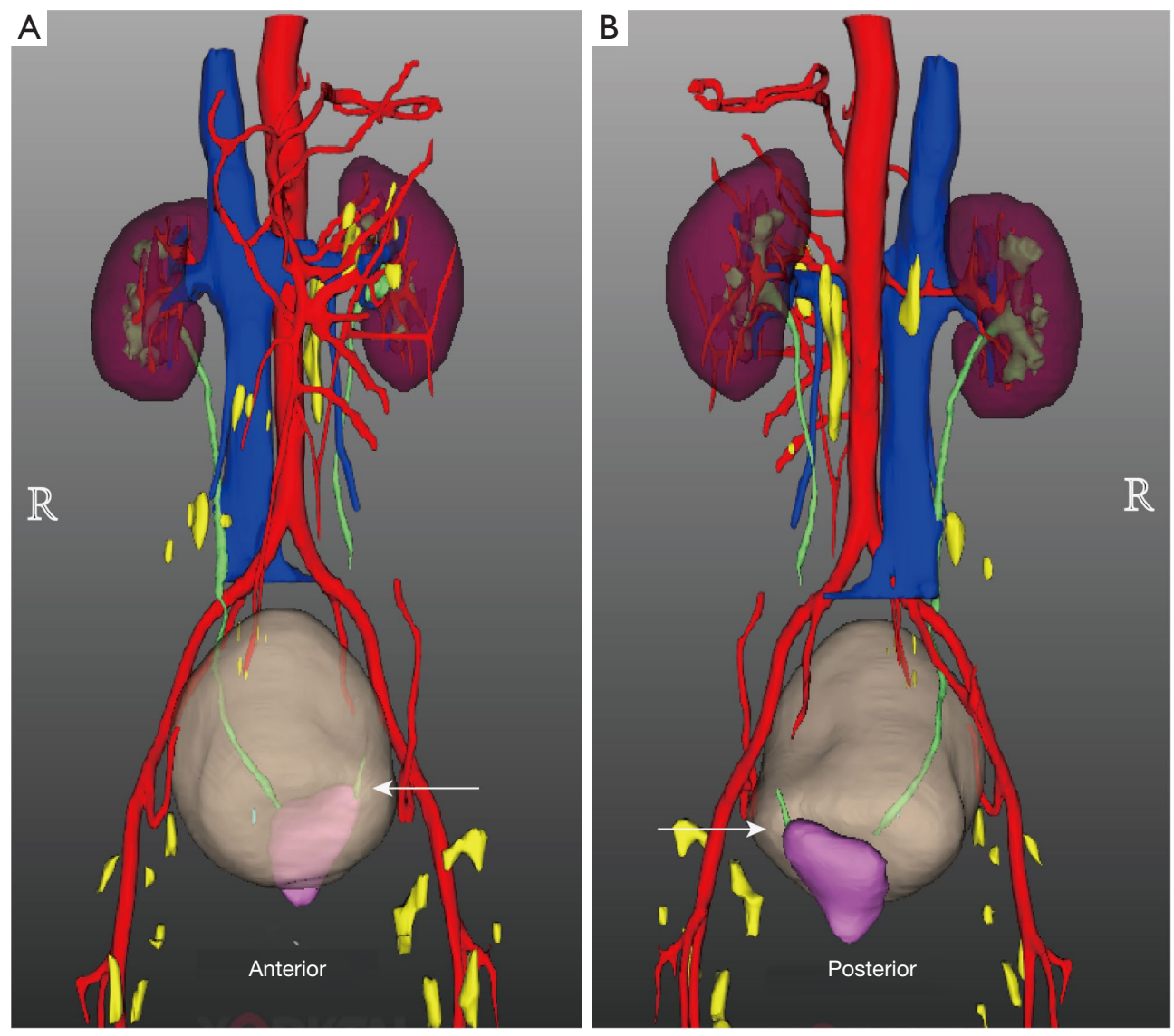

Figure 2 Preoperative three-dimensional computer tomography reconstruction demonstrates the location of ureterovaginal fistula. (A) Anterior view of the three-dimensional image. (B) Posterior view of the three-dimensional image. Different colors show different organs: gray, bladder; green, ureter; pink, vagina. The ureterovaginal fistula is marked by a white arrow.

performed routinely to confirm that the D-J stent stayed in the appropriate position. Two weeks after surgery, the nephrostomy tube was clamped but not removed. The D-J stent was removed one or two months after surgery. Then, patients had anterograde examination nephrostomy tubes placed two months after surgery. Since no ureteral narrowing or contrast extravasation was confirmed, the nephrostomy could be removed. Finally, the patients were instructed to undergo an ultrasound examination annually.

\section{Statistical analysis}

Data were analyzed using SPSS software version 22.0 (IBM Corporation, Armonk, NY, USA). Measurement data are expressed as the mean (range), and enumeration data are expressed as numbers (percentages).

The study was conducted in accordance with the
Declaration of Helsinki (as revised in 2013). The study was approved by the Ethics Committee of Peking University First Hospital (NO. 2019134), and individual consent for this retrospective analysis was waived.

\section{Results}

All patients were admitted to the hospital with the main complaint of leaking urine from the vagina. The cause of the ureterovaginal fistula in four patients was due to a previous hysterectomy. The mean time from fistula diagnosis to robotic repair surgery was 14.5 (range, 3-36) months. The results are described in detail in Table 1. The mean age of the patients was 50.3 (range, 37-65) years, the mean operative time (OT) was 137 (range, 116-171) minutes, and the mean estimated blood loss (EBL) was 25 (range, 10-50) $\mathrm{mL}$. The mean body 

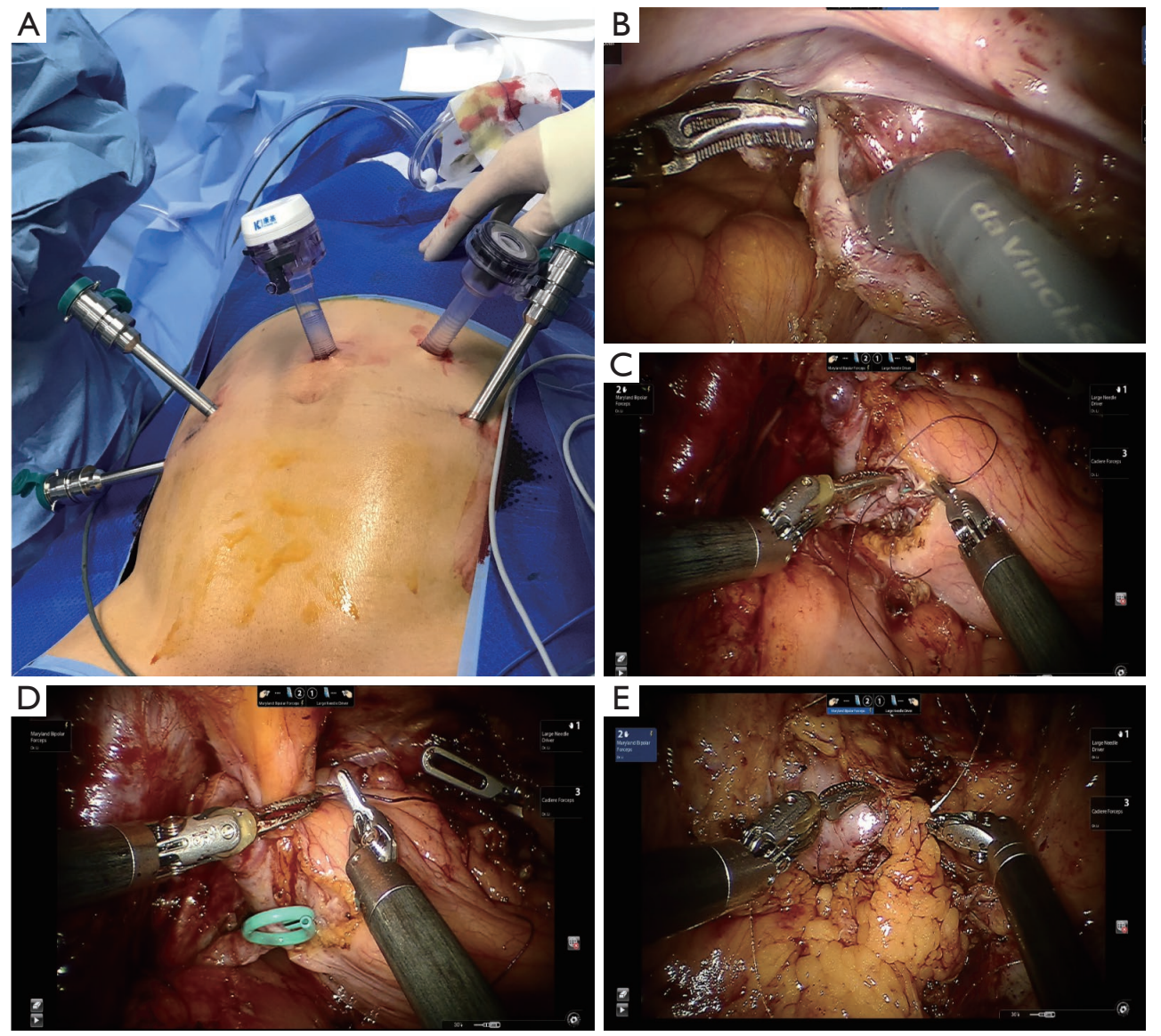

Figure 3 Description of robot-assisted management of ureterovaginal fistula. (A) Standard transperitoneal five-port placement. (B) The distal ureterolysis shows the ureteral stricture. (C) The mucosa-mucosal anastomosis is created. (D) The bladder is sutured with a psoas hitch. (E) Omental interposition flap is put above the repair.

mass index (BMI) was 26.1 (range, 23.4-30.0) kg/m², and two patients were overweight (BMI $\left.\geq 25 \mathrm{~kg} / \mathrm{m}^{2}\right)$. All four robotic surgeries were effectively completed, and no case required open conversion. None of them developed intraoperative complications or needed blood transfusions. According to the Clavien-Dindo classification system (9), no postoperative complications of high grade (grade III and IV) occurred within one month of surgery. There was only one patient who had a fever (grade II) and it was treated and resolved quickly by the use of antibiotics. The mean length of postoperative hospital stay was 5.3 (range, 4-7) days. To date, the median follow-up duration has been 15.8 (range, 6-24) months, and the symptoms of urine leakage have completely disappeared. Ureteroscopy was performed routinely to check for stenosis or poor healing of the anastomosis when the D-J stents were removed 2-3 months after the operation. The contrast-enhanced CT of case 1 who had a right UVF displayed a left ureteral space with hydronephrosis. Then, ureteroscopy biopsy showed squamous cell carcinoma of the cervix due to a recurrence of cervical cancer. There was no obvious abnormality in the right kidney or ureter. No patients reported obvious discomfort during the follow-up. Magnetic resonance urography (MRU) showed a well-healed anastomosis, and the upper urinary tract was unobstructed (Figure 4). Therefore, there was $100 \%$ success without serious complications, such as leakage of urine and progressive hydronephrosis, during the 6 to 24 months of follow-up.

\section{Discussion}

UVF is a common and severe iatrogenic injury, and it is caused by obstetric and gynecological operations, especially hysterectomy for gynecological malignant 


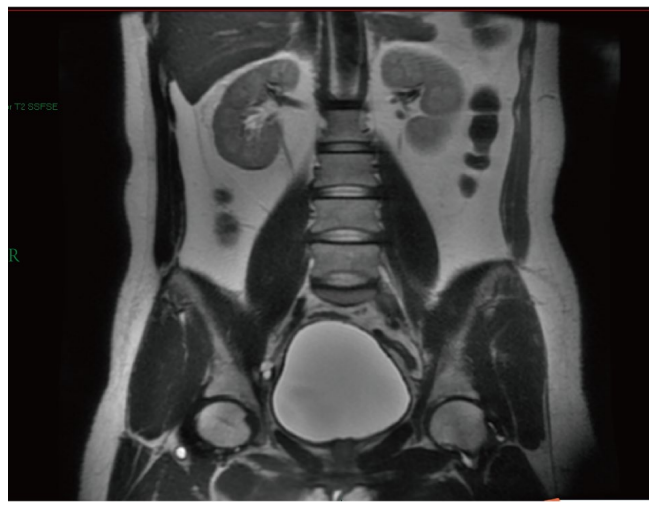

Figure 4 The magnetic resonance image at the follow-up is normal completely.

tumors (10). There are some predisposing factors to fistula formation, such as intraoperative visceral injury with thermal power, sutures or sharp dissection, as well as comorbidities that influence exposure or surgical healing. In addition, some patients underwent minimally invasive radical hysterectomy, which may be an independent risk factor for fistula formation (2). In general, the left ureter is more susceptible to injury because it has a closer relationship with the cervix than the contralateral ureter (11). Ureteral injury is often due to the following reasons: (I) potential injury after gynecological surgery because of the proximity of the female genital tract to the lower urinary tract. (II) Surgeons are not familiar with adjacent ureteral anatomy, which makes the ureter at risk of injury. (III) The intraoperative excision of the ureter damages the blood supply, resulting in ischemia and necrosis of the ureter. (IV) Anatomic variation exists as a result of endometriosis, tumors, and other reasons, and the ureter is injured by mistake during the operation.

At present, it is controversial to select the appropriate surgical time. Early surgery is recommended by most scholars because it can reduce the possibility of renal function damage caused by ureteral stenosis, shorten the treatment time, reduce the cost of hospitalization, and eliminate the physical and mental anguish of patients with UVF (12). However, delayed repair can promote inflammation around the ureter caused by urinary leakage and can prevent the ability of the tissues to heal (13). Although small fistulas can heal spontaneously after ureteral injury, scar healing often complicates ureteral strictures in the long term. Some minor scar healing can be prevented by indwelling D-J stents, but some cases still have a recurrence of ureteral strictures after D-J stent removal, which requires surgical intervention (14). UVF is different from vesicovaginal fistula and should be treated as soon as possible, and the timing and approach of the operation should be determined according to the individual condition. If conditions are not good, nephrostomy can be performed to protect renal function. Before the management of surgery, endoscopic therapy with D-J stent placement could be chosen. Selzman et al. (15) reported that 7 patients with UVF were cured by placing D-J stents in his study. However, once conservative measures fail, such as catheterization failure or urine leakage relief, patients should proceed to surgical management as soon as possible. At present, minimally invasive techniques are often chosen, including laparoscopic surgery and robotic surgery (16). Ureteral reimplantation should be performed at the lower injury site near the bladder, and ureteroureterostomy can be performed when ureteral replantation is difficult at the higher injury site. General principles should be carried out, including ensuring that the ureteral scar tissue is completely removed, there is a tension-free anastomosis, there is no distortion of the ureter, there is a good ureteral blood supply and there is avoidance of urine leakage. Although laparoscopic repair has many advantages, ureteral reconstruction reports have highlighted the technical difficulty of intracorporeal suturing during ureteral anastomosis and the difficulty of dissecting in the limited pelvic working space $(17,18)$. This drawback has been overcome by incorporating the assistance of robots for repair.

The surgical system provides significant advantages for the gross identification of viable structures within dense scar tissue as well as the identification of healthy ureters for reimplantation. Gellhaus et al. (19) reported that robotic repair of UVFs during obstetrics and gynecology surgery is associated with good outcomes and appears safe and feasible. In 2008, Laungani et al. (20) reported three pure robotic ureteroneocystostomies for the repair of complex UVFs. A six-port approach was used, and all patients had a good outcome. Subsequently, Siddighi and Carri (21) reported that they successfully repaired UVFs robotically using five ports in three patients. The sparsity of the literature, as well as small case series, reflects the exploration of ureteral implantation for UVF in Table 2 (2,16,19-24). Based on the surgical outcomes of the considered studies, the benefits of robotic-assisted implantation are highlighted to a certain extent in the previous literature. The average operative time and blood loss were 190 minutes and $44 \mathrm{~mL}$, respectively. 
Table 2 the literatures of robotic-assisted management of UVF

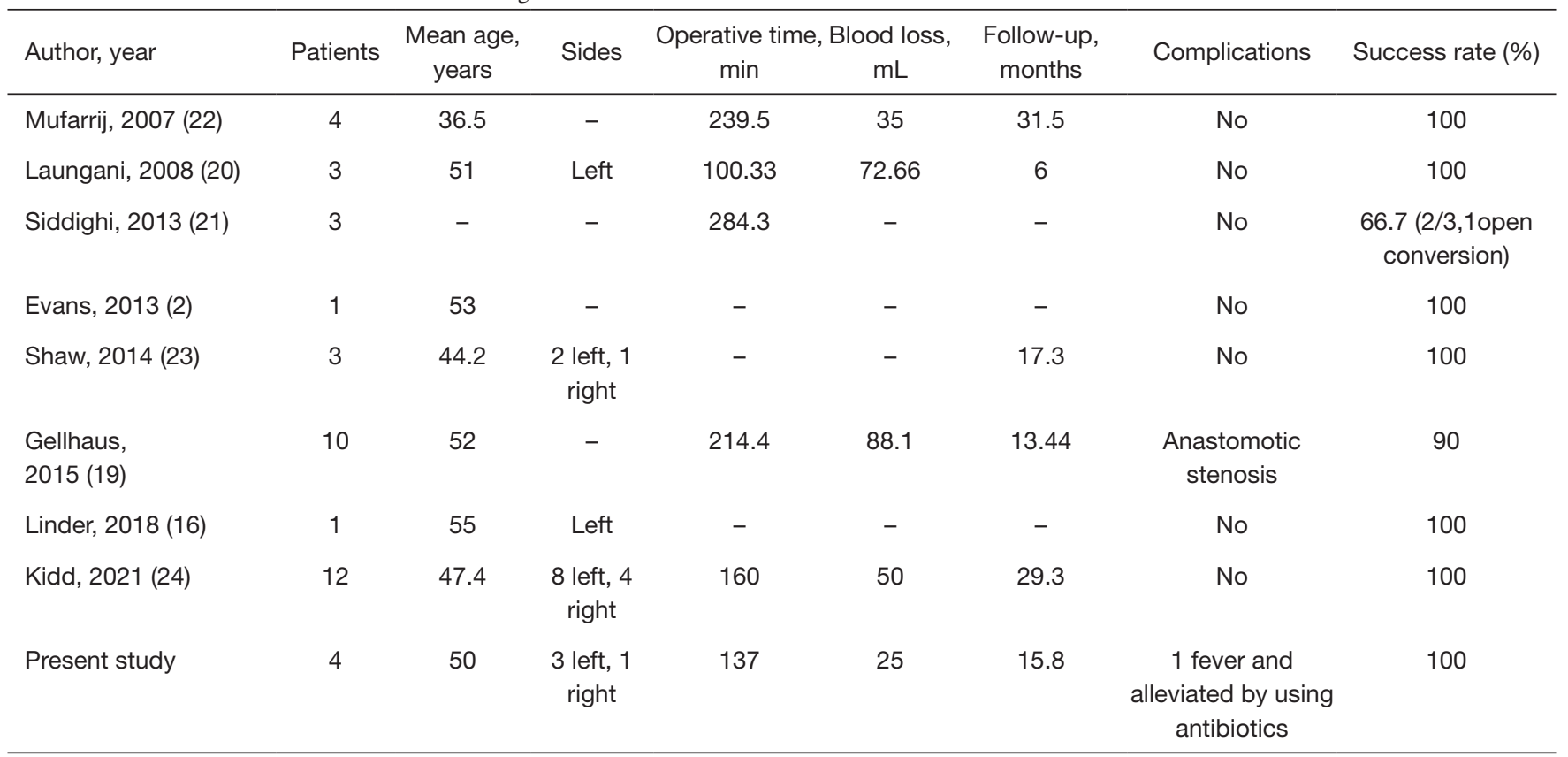

UVF, ureterovaginal fistula.

One patient was converted to open surgery and successfully completed the UVF because of severe adhesions between the ureter and vessels in Siddighi's series. There were no severe complications, and only one postoperative fever was noted which was quickly relieved by antibiotics. We reported four patients in whom the whole robotic surgery was finished successfully with a shorter operational time. The blood loss was the least in literature for robotic surgery. In addition, preoperative three-dimensional reconstruction was first used in the management of UVF, which is not reported in the worldwide literature. With the development of imaging technology, a three-dimensional visualization technique based on routine CT images has gradually emerged and been used in clinical operations, which can help assess the anatomic relationship between the targeted area and peripheral structure and can improve the surgical efficacy $(25,26)$. Therefore, we performed the technology to analyze the operative features and obtained a good clinical outcome.

Our experience with robotic techniques shows advantages in the management of UVFs. Although our study may appear to be another small study on the development of robotic technology, it is recommended that surgeons performing robotic surgery of the upper and lower urinary tracts will possibly be able to use similar skills to perform replantation or ureteroureterostomy. Surgeons possessing both reconstructive and minimally invasive surgical abilities could reliably manage UVFs with a robotic approach.

There are some limitations to our study. Although all patients so far have a good outcome to date, longer followup is necessary to assess the long-term efficacy of our results. Our results are limited by the small number of patients. It should be mentioned that UVFs are relatively rare, so a large patient cohort is difficult to generate. However, robotic surgery is gradually becoming a mainstream method, and we are optimistic that this initial report can serve as a foundation for developing robotic standardized management of UVFs.

\section{Conclusions}

In conclusion, our initial experience demonstrates that robotic ureteral reimplantation is a feasible and effective technique for managing UVFs. However, future studies including larger patient numbers and long-term follow-up of cases are required.

\section{Acknowledgments}

Funding: None. 


\section{Footnote}

Reporting Checklist: The authors have completed the STROBE reporting checklist. Available at https://dx.doi. org/10.21037/tau-21-454

Data Sharing Statement: Available at https://dx.doi. org/10.21037/tau-21-454

Peer Review File: Available at https://dx.doi.org/10.21037/ tau-21-454

Conflicts of Interest: All authors have completed the ICMJE uniform disclosure form (available at https://dx.doi. org/10.21037/tau-21-454). XL and LZ serve as unpaid editorial board members. The other authors have no conflicts of interest to declare.

Ethical Statement: The authors are accountable for all aspects of the work in ensuring that questions related to the accuracy or integrity of any part of the work are appropriately investigated and resolved. The study was conducted in accordance with the Declaration of Helsinki (as revised in 2013). The study was approved by the Ethics Committee of Peking University First Hospital (No. 2019134) and individual consent for this retrospective analysis was waived.

Open Access Statement: This is an Open Access article distributed in accordance with the Creative Commons Attribution-NonCommercial-NoDerivs 4.0 International License (CC BY-NC-ND 4.0), which permits the noncommercial replication and distribution of the article with the strict proviso that no changes or edits are made and the original work is properly cited (including links to both the formal publication through the relevant DOI and the license). See: https://creativecommons.org/licenses/by-nc-nd/4.0/.

\section{References}

1. Gilmour DT, Das S, Flowerdew G. Rates of urinary tract injury from gynecologic surgery and the role of intraoperative cystoscopy. Obstet Gynecol 2006;107:1366-72.

2. Evans JM, Karram MM, Mahdy A, et al. Urinary tract injury at the time of laparoscopic and robotic surgery: presentation and management. Female Pelvic Med Reconstr Surg 2013;19:249-52.
3. Ozdemir E, Ozturk U, Celen S, et al. Urinary complications of gynecologic surgery: iatrogenic urinary tract system injuries in obstetrics and gynecology operations. Clin Exp Obstet Gynecol 2011;38:217-20.

4. Lee JS, Choe JH, Lee HS, et al. Urologic complications following obstetric and gynecologic surgery. Korean J Urol 2012;53:795-9.

5. Hwang JH, Lim MC, Joung JY, et al. Urologic complications of laparoscopic radical hysterectomy and lymphadenectomy. Int Urogynecol J 2012;23:1605-11.

6. Lanfranco AR, Castellanos AE, Desai JP, et al. Robotic surgery: a current perspective. Ann Surg 2004;239:14-21.

7. Ahlering TE. Robotic versus laparoscopic radical prostatectomy. Nat Clin Pract Urol 2004;1:58-9.

8. McCulloch P, Altman DG, Campbell WB, et al. No surgical innovation without evaluation: the IDEAL recommendations. Lancet 2009;374:1105-12.

9. Clavien PA, Barkun J, de Oliveira ML, et al. The ClavienDindo classification of surgical complications: five-year experience. Ann Surg 2009;250:187-96.

10. Lim MC, Lee BY, Lee DO, et al. Lower urinary tract injuries diagnosed after hysterectomy: seven-year experience at a cancer hospital. J Obstet Gynaecol Res 2010;36:318-25.

11. Hillary CJ, Osman NI, Hilton P, et al. The Aetiology, Treatment, and Outcome of Urogenital Fistulae Managed in Well- and Low-resourced Countries: A Systematic Review. Eur Urol 2016;70:478-92.

12. Kostakopoulos A, Deliveliotis C, Louras G, et al. Early repair of injury to the ureter or bladder after hysterectomy. Int Urol Nephrol 1998;30:445-50.

13. Alonso Gorrea M, Fernandez Zuazu J, Mompó Sanchis JA, et al. Spontaneous healing of ureterogenital fistulas: selection criteria. Eur Urol 1986;12:322-6.

14. Upadhyay AM, Kunwar A, Shrestha S, et al. Managing Ureterovaginal Fistulas following Obstetric and Gynecological Surgeries. J Nepal Health Res Counc 2018;16:233-8.

15. Selzman AA, Spirnak JP, Kursh ED. The changing management of ureterovaginal fistulas. J Urol 1995;153:626-8.

16. Linder BJ, Frank I, Occhino JA. Extravesical robotic ureteral reimplantation for ureterovaginal fistula. Int Urogynecol J 2018;29:595-7.

17. Hemal AK, Nayyar R, Gupta NP, et al. Experience with robot assisted laparoscopic surgery for upper and lower benign and malignant ureteral pathologies. Urology 2010;76:1387-93. 
18. Li HZ, Ma X, Qi L, et al. Retroperitoneal laparoscopic ureteroureterostomy for retrocaval ureter: report of 10 cases and literature review. Urology 2010;76:873-6.

19. Gellhaus PT, Bhandari A, Monn MF, et al. Robotic management of genitourinary injuries from obstetric and gynaecological operations: a multi-institutional report of outcomes. BJU Int 2015;115:430-6.

20. Laungani R, Patil N, Krane LS, et al. Robotic-assisted ureterovaginal fistula repair: report of efficacy and feasiblity. J Laparoendosc Adv Surg Tech A 2008;18:731-4.

21. Siddighi S, Carr KR. Lighted stents facilitate roboticassisted laparoscopic ureterovaginal fistula repair. Int Urogynecol J 2013;24:515-7.

22. Mufarrij PW, Shah OD, Berger AD, et al. Robotic reconstruction of the upper urinary tract. J Urol 2007;178:2002-5.

23. Shaw J, Tunitsky-Bitton E, Barber MD, et al.

Cite this article as: Yuan C, Wang J, Cheng S, Li Z, Xu C, Zhu W, Fan S, Yang K, Li X, Zhou L. Robotic ureteral reimplantation for the management of ureterovaginal fistula: four cases at a single center. Transl Androl Urol 2021;10(10):3705-3713. doi: 10.21037/tau-21-454
Ureterovaginal fistula: a case series. Int Urogynecol J 2014;25:615-21.

24. Kidd LC, Lee M, Lee Z, et al. A Multi-Institutional Experience with Robotic Vesicovaginal and Ureterovaginal Fistula Repair After Iatrogenic Injury. J Endourol 2021. [Epub ahead of print]. doi: 10.1089/end.2020.0993.

25. Wang Z, Qi L, Yuan P, et al. Application of ThreeDimensional Visualization Technology in Laparoscopic Partial Nephrectomy of Renal Tumor: A Comparative Study. J Laparoendosc Adv Surg Tech A 2017;27:516-23.

26. Tolkach Y, Thomann S, Kristiansen G. Three-dimensional reconstruction of prostate cancer architecture with serial immunohistochemical sections: hallmarks of tumour growth, tumour compartmentalisation, and implications for grading and heterogeneity. Histopathology 2018;72:1051-9. 